Canadian Journal of Civil Engineering

Canadian

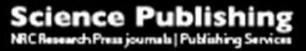
Revue canadienne de génie civil

\title{
Infrastructure Crisis - A Proposed National Infrastructure Policy for Canada
}

\begin{tabular}{|r|l|}
\hline Journal: & Canadian Journal of Civil Engineering \\
\hline Manuscript ID & cjce-2016-0468.R1 \\
\hline Danuscript Type: & Article \\
\hline Complete List of Authors: & $\begin{array}{l}\text { Mirza, Saeed; McGill University, Department of Civil Engineering and } \\
\text { Applied Mechanics } \\
\text { Ali, M. Shafqat; McGill University, Department of Civil Engineering and } \\
\text { Applied Mechanics }\end{array}$ \\
\hline $\begin{array}{r}\text { Please Select from this Special } \\
\text { Issues list if applicable: }\end{array}$ & N/A \\
\hline Keyword: & $\begin{array}{l}\text { Deterioration; infrastructure crisis; national infrastructure policy; } \\
\text { infrastructure bank; rehabilitation }\end{array}$ \\
\hline \multicolumn{2}{|c}{} \\
\hline
\end{tabular}

SCHOLARONE ${ }^{\text {m }}$

Manuscripts 


\section{Infrastructure Crisis - A Proposed National Infrastructure Policy for Canada}

Saeed Mirza

Professor Emeritus, Department of Civil Engineering and Applied Mechanics, McGill University,

Room 492, Macdonald Engineering Building, 817 Sherbrooke Street West, Montreal, QC, Canada. Email: saeed.mirza@mcgill.ca

Telephone: 514-398-6862; Fax: 514-398-7361

\section{Shafqat Ali}

Adjunct Professor, Department of Civil Engineering and Applied Mechanics, McGill University, Room 492, Macdonald Engineering Building, 817 Sherbrooke Street West, Montreal, QC, Canada. Email: muhammad.ali2@mail.mcgill.ca. 


\begin{abstract}
The paper proposes a National Infrastructure Policy (NIP) for Canada, including establishing a national infrastructure bank to overcome the current dire financial and other difficulties in renewal of Canada's extensively deteriorated infrastructure, and for construction of new infrastructure to fulfill the society's new needs. After examining the deteriorated state of infrastructure in Canada, the U.S.A. and the world, the current infrastructure deficits and the consequences of inaction, along with the views of community and political leaders to establish infrastructure priorities and the needed actions, an NIP is proposed for consideration by all parties involved with infrastructure. The associated financial needs to upgrade the infrastructure to an acceptable level are reviewed, along with the consequences of any delay in the needed repairs and renewal.
\end{abstract}

Keywords: Deterioration; infrastructure crisis; implementation; infrastructure policy; infrastructure bank; policy; priorities; public services; renewal; rehabilitation. 


\section{Introduction}

Sustainable infrastructure involves conceiving, designing, constructing, operating, maintaining, and when needed, repairing/rehabilitating the existing infrastructure facilities to maintain or upgrade the existing social, economic and environmental conditions in any community to ensure human equity, and sustainable functioning of the community, resulting in an improved quality of life for all citizens. Building for the present and future communities requires long-term planning, including knowledge of the projected population growth, keeping up with the technological innovations, and dealing with the increasing impact of extreme natural and manmade events, and ensuring the delivery of essential public services without disruption. "Infrastructure is a dynamic concept, evolving and expanding to include new categories of assets that are critical for the functioning of the economy and the society"; it facilitates the day-to-day functioning of all citizens and it directly influences the quality of life of any community (Uddin et al. 2013; Hill et al. 2012; Newman et al. 2008). Infrastructure normally comprises structures, systems, facilities and services, which serve a community in a large or small urban or rural area, to facilitate its functioning with an acceptable quality of life. It would include all types of buildings, roads, bridges, tunnels, water supply and sewage disposal systems, canals, ports, airports, electrical grids, telecommunications, and many other systems. According to Newman et al. (2008), "the importance of sustainable infrastructure to a community and its capacity for innovation is similar to the foundation the human skeleton plays in the overall structuring, functioning and the health of the body".

This paper summarizes briefly the state of deteriorating infrastructure in Canada, the U.S.A. and the world, the associated deficits and consequences of inaction. The views of community and 
political leaders to establish infrastructure priorities and needed actions are considered in proposing an NIP for consideration by all parties involved with infrastructure.

\section{The World Infrastructure Scenario}

The current extensive deterioration in infrastructure assets around the world constitutes a serious threat to the health and safety of the world population. Besides significantly degrading the environment and the economic growth, the infrastructure deterioration and malfunctioning considerably lowers the international competitiveness of these countries, which in turn, downgrades their quality of life (SWISSRE 2016; The Economist 2016; Oliver 2015; UK National Infrastructure Plan 2013; Dunlop 2008). According to the McKinsey Global Institute (MGI 2013a, 2013b), an estimated \$57 trillion needs to be invested in world's infrastructure between 2013 and 2030. MGI contends that there are clear ways to create more and better infrastructure for less. The Institute recommends practical steps to reduce the needed infrastructure spending by $40 \%$, amounting to an annual saving of about $\$ 1$ trillion by increasing infrastructure productivity. Insufficient or inadequate infrastructure and the resulting congestion, power outages, and the lack of access to safe water and roads are a serious global concern. The principal information from the McKinsey Global Institute reports (MGI 2013a, 2013b) is briefly summarized here for completeness.

\subsection{Basic Global Infrastructure Needs}

MGI used three approaches to estimate the basic infrastructure needs around the world, involving roads, railways, ports, airports, water and telecommunications, but excluding social infrastructure, such as schools and hospitals. These estimates involve a deficit of US\$ 57 trillion to US\$ 67 trillion from 2013 to 2030 in 2010 US dollars (Figure 1). These projections are based on historic spending (US\$ 62 trillion), the ratio of infrastructure stock to the GDP (US\$ 67 
trillion) and the external estimates (US\$ 57 trillion). These estimates do not include any maintenance backlogs, fulfilment of the development goals of emerging nations, the need to increase infrastructure resilience to extreme events and any future climate change and the current financial constraints and the resulting crises in almost all countries (MGI 2013a). When the social infrastructure needs, the interest rates and the on-going inflation, and the rapidly increasing infrastructure deterioration rates are considered, these estimates could easily increase to well above US\$100 trillion. It should be noted that these estimates are higher "than the total value of world's infrastructure, and is nearly $60 \%$ more than the worldwide expenditure of US\$ 36 trillion on infrastructure over the past 18 years - an average of about US\$ 2 trillion per year" (MGI 2013a).

Presently, the political and public discourse is focused on the adequacy of the available financing to meet the rapidly growing infrastructure needs, and is dominated by the "infrastructure gap or deficit" and the accompanying challenges. Unfortunately, this has diverted attention from the important and urgent issues of the ways to provide more, and better quality infrastructure in a less costly manner. MGI has urged the governments around the world to rethink of the ways in which they can, in partnership with the private sector "elect, design, deliver and manage infrastructure projects and make more out of the infrastructure already in place". The Institute emphasizes that it is not necessary "to reinvent the wheel" and recommends a unique opportunity to "eliminate waste, improve project selection procedures, streamline their delivery, and use available best practices".

\subsection{Possible Savings in Global Infrastructure Expenditure}

MGI recommends three broad methods to effect annual savings of about $\$ 1$ trillion in global infrastructure expenditures: optimization of project portfolios (US\$200 billion), streamlining of 
delivery (US\$400 billion), and making the most out of the existing infrastructure, instead of investing in new expensive infrastructure facilities (US\$400 billion).

Improvements in governance systems can assist with increased productivity. Implementing these reforms and introduction of the latest best practices in each country can reduce "the vast infrastructure challenge to reasonably manageable proportions, and eliminate the current paralysis". These can form the foundation for continuous economic growth and development.

In addition, many governments, particularly in developing markets, hold a stock of cashgenerating assets. The world's infrastructure stock is valued at an estimated US $\$ 48$ trillion. Some of these assets are already profitable, while others could turn a profit if operations are improved; for example, the Government of Greece recently agreed to sell a network of 14 regional airports to a consortium, and in 2013, the Brazilian government sold for nearly US\$800 million a 30-year concession to operate Confins Airport in the state of Minas Gerais.

\subsection{Historical Infrastructure Spending Data}

Historical spending data available for 12 countries (perpetuity model) was used by MGI to extrapolate the value of the global infrastructure stock, which was found to average around $70 \%$ of the country's GDP, with Japan being the over-investor. As stated earlier, an estimated US\$57 trillion would be needed from 2013 to 2030 (an average annual investment of about US\$3.7 trillion) to maintain the value of infrastructure assets at an average of 0.7 of the country's GDP.

The challenges faced in infrastructure investment comprise seriously constrained public sector finances, decreased borrowing power, and increased regulation stringencies in the banking system (MGI 2013a). Any shortcomings in meeting the recommended infrastructure needs would only negatively influence the country's GDP and would increase unemployment. Moreover, it 
was noted that the public-private partnership (PPP) projects have accounted for only a surprisingly low $15 \%$ of all infrastructure ventures.

MGI evaluated the future infrastructure needs by asset class in consultation with the Organization for Economic Cooperation and Development, the International Energy Agency and Global Water Intelligence, and noted the overall need for US\$ 57 trillion (about US\$3.7 trillion a year) between 2013 and 2030. After detailed consultation with key government and private sector parties interested in infrastructure, MGI recommended that infrastructure owners must adopt proven best practices to increase infrastructure productivity to achieve savings of about $40 \%$ of the overall infrastructure expenditure; this could amount to worldwide annual savings of about US\$1 trillion over the same period. For Canada, these savings could amount to about one billion dollars annually (InfraGuide 2007)

\subsection{Frequency and Intensity of Natural Hazards}

Over the past nearly 25 years, natural hazards (such as, earthquakes, hurricanes, tsunamis, wildfires, etc.), and man-made hazards (such as terrorist attacks, operational accidents, and failures resulting from design and/or construction errors and other causes), have increased significantly in their frequency and intensity. A summary of the natural catastrophes and manmade disasters from 1996 to 2015, in terms of number of disasters, number of victims, and the insured catastrophe losses in US dollars is presented by the Economist (2016), and are summarized in Figure 2. According to the Economist data, the maximum cost of all losses was US $\$ 421$ billion in 2011, which is about 20 to $25 \%$ of the annual investment in infrastructure worldwide. This should cause serious concern because this situation can worsen considerably in some regions with the impact of impending climate change. Consequently, designing and managing infrastructure assets must receive the highest priority with all countries. 


\section{State of Infrastructure in Canada and the U.S.A.}

Several infrastructure-related tragedies, involving bridge collapses, water pipeline breakages, water supply contaminations and outbreaks of water-related diseases, and transit and rail accidents have occurred in Canada, the USA and around the world over the recent past. Most of these tragedies reflect unacceptable levels of deterioration that have accumulated over the years; this situation must change immediately to ensure adequate and safe functioning of all communities. Many of these tragedies are attributable to poor quality control during design and construction, lack of scientific life-cycle maintenance, and inadequate management practices throughout the asset service life (FCM 2008; Mirza 2006; Infrastructure Council of Manitoba 2000; Mirza 1998). Consequently, many of these assets have failed well before the end of their expected service life, posing serious threat to public health and safety, and the environment, requiring urgent improvements in all aspects of infrastructure, which are posing a serious threat to the productivity, competitiveness and economic development of the cities, regions and the quality of life of all citizens.

\subsection{The American Scene}

Based on the physical condition and the needed investment for infrastructure amelioration, the American Society of Civil Engineers (ASCE) issues a Report Card every four years for America's Infrastructure, evaluates the condition of America's infrastructure in the familiar school report form, along with a letter grade assigned to each infrastructure category and the estimated investment required (ASCE 2013). The overall state of their infrastructure was given a failure grade 'D' in the latest ASCE (American Society of Civil Engineers 2013) infrastructure report card in 2013. The annual investment to improve the quality of the U.S. infrastructure and to raise its average grade to B was estimated at US\$ 454 billion. If the needed amelioration is not 
implemented, the increased cost to the American businesses would be about US\$1.2 trillion and to the American households about US\$61 billion.

\subsection{The Canadian Scene}

According to the latest survey results, the total value of Canada's core municipal infrastructure assets is estimated at C\$1.1 trillion dollars, or about $\mathrm{C} \$ 80,000$ per household (CIRC 2016). A large part of Canada's infrastructure was constructed between the 1950's and the 1970's, and its extensively deteriorated condition is manifested in the serious distress and failure of several assets, involving loss of life, injuries and large economic losses (Gagnon et al. 2008). Most of Canada's infrastructure has already reached the end of its useful service life; an astounding $28 \%$ of the assets are between 80 and 100 years old (CIRC 2016; TRM 2003). While many of these older infrastructure assets are in urgent need of rehabilitation or replacement, there are also many newer facilities that are deteriorating quite rapidly due to inadequate or deferred maintenance and the badly needed repairs, mostly because of lack of adequate financing over the entire service life.

The current infrastructure crisis threatens Canada's economy and international competitiveness, which will significantly influence the quality of life of all citizens. The present federal government has committed to ameliorate Canada's infrastructure problems by agreeing to finance the badly needed repairs/rehabilitation/replacement by incurring a deficit of about $\mathrm{C} \$ 10$ billion over the next few years (Table 1). The Government recently announced an investment of about $\mathrm{C} \$ 80$ billion in the public infrastructure over the next decade, including the $\mathrm{C} \$ 53$ billion New Building Canada Plan for provincial, territorial and municipal infrastructure, which would build up on the existing C\$33 billion funding committed in 2007 (Infrastructure Canada 2016; Finance Canada 2016). 


\subsection{Canada's Infrastructure Deficit and Urgent Needs}

In Canada, the infrastructure deficit - the difference between the funds available from all sources and the funding needed for maintenance, repair, rehabilitation and replacement of existing deteriorated infrastructure assets - is normally used as an indicator of the state of assets and to essentially quantify the infrastructure crisis. Over the past few decades, Canada's municipal infrastructure has fallen increasingly into serious disrepair, due to:

- Lack of quality control and innovation in conception, design and construction

- Ageing of infrastructure assets

- $\quad$ Lack of sustained funding

- Years of deferred or inadequate maintenance

- Lack of a detailed inventory of all assets in every jurisdiction, their construction, maintenance and repair/rehabilitation history, and the associated costs, needed for scientific management of infrastructure assets (Asset Management).

The results of the 2016 Canadian Infrastructure Report Card (CIRC) showed that nearly 35\% of municipal roads, municipal buildings, sport and recreation facilities and public transit assets are in urgent need of attention and at risk of rapid deterioration, thereby increasing the risk of service disruption.

The issues of repairing and rehabilitating the existing deteriorated infrastructure, and construction of new infrastructure to serve the evolving needs of communities across Canada over the short and long terms require careful and thorough consideration by all parties involved. The tenure of a government is normally four years, while different infrastructure assets continue to serve the society for decades; some have lasted well over 100 years. Consequently, there is an urgent need for a national infrastructure policy (NIP) to assist the governments to address all of 
the short- and long-range issues involved, and to provide guidance to the practitioners for the relevant changes in design, construction and life-time management of assets. It must also guide the academia in shifting from a principally "design" focused curriculum to one that places significant emphasis on all aspects of sustainable management of infrastructure assets, including their regular maintenance. The policy should be designed to help the relevant government and other officials to develop solutions for all current problems and future issues arising from any climate change and other unforeseen events, within the available limited resources. It must also emphasize training of engineers and retraining of practitioners in regular maintenance of existing and new assets. The various issues that have led to the current crisis situation are summarized along with the reasons to urgently establish a national infrastructure policy.

The CIRC (2016) survey estimated the current value of Canada's core municipal infrastructure to be C\$1.1 trillion; Canada's GDP in 2015 is listed at US\$1.96 trillion, which would be about C\$2.3 trillion. When the value of the infrastructure under the jurisdictions of the provincial, territorial and federal governments, the private sector and the energy infrastructure are added, the total worth of infrastructure could easily fulfill the rule of thumb requirement of infrastructure value being more than $70 \%$ of Canada's GDP (about C\$2.3 trillion). However, in view of the dire condition of the various infrastructure assets, it is urgent to establish the additional investment needed in all types of infrastructure under all jurisdictions (Table 1).

The previous and current estimates of infrastructure needs in Canada, including the energy infrastructure, would point to a need for over one trillion dollars over the next 15 to 20 years. The present federal investments amount to about $\mathrm{C} \$ 4$ billion annually, while the provincial investments range between 2 to 4 billion Canadian dollars annually, and the future municipal infrastructure investments would be between 2 and 3 billion dollars annually. It must be noted 
that the municipalities own about $56.8 \%$ of all infrastructure in Canada; however, they receive only about $8 \%$ of the total tax revenue, and consequently the municipalities constantly depend on other levels of government sources for funding - a situation which needs to be resolved urgently.

\subsection{Infrastructure Needs - World, U.S.A. and Canada}

A summary of the infrastructure needs for the world, U.S.A. and Canada is presented in Table 2. For the world and the U.S. infrastructure, the numbers represent total needs, while for Canada, the needs for rehabilitation of deteriorated infrastructure is listed along with the needs for new infrastructure to serve the new and changing needs of the society. As mentioned earlier, municipal infrastructure constitutes about $56.8 \%$ of Canada's infrastructure, with the federal, provincial and territorial $(\mathrm{F} / \mathrm{P} / \mathrm{T})$ infrastructure comprising the remaining $43.2 \%$. Assuming that the projected $\mathrm{F} / \mathrm{P} / \mathrm{T}$ infrastructure upgrading needs are similar to those of the municipal infrastructure, these $\mathrm{F} / \mathrm{P} / \mathrm{T}$ needs would be about $76 \%(=43.2 / 56.8 \%)$ of the municipal infrastructure needs.

\subsection{Energy Infrastructure in Canada}

According to the Conference Board of Canada, there are about $71,000 \mathrm{~km}$ of energy pipelines in Canada. The investment needed to rehabilitate this deteriorating infrastructure and to boost power generation and transmission (electrical, oil and gas) is approximately C $\$ 300$ billion. This includes new oil and gas extraction and transportation systems (basically the pipeline systems), costing approximately $\mathrm{C} \$ 100$ billion (US\$78 billion), resulting in the total energy sector needs of approximately C\$400 billion (US\$312 billion).

In summary, Canada faces tremendous infrastructure needs, and action is needed in the following areas: 
- Scientific management of all infrastructure assets requires development of a national inventory of the assets in each jurisdiction, including all construction, maintenance, repair/rehabilitation details).

- Consideration of total life cycle costs, consisting of engineering, economic, environmental and social costs, instead of the current practice of consideration of the lowest construction costs, without any initial consideration of maintenance, repair/rehabilitation, decommissioning and demolition and sustainable disposal at the end of service life.

- New technical developments consisting of education, including design of sustainable systems, their life-cycle performance and costing, with consideration for impact of any future climate change, scientific construction, maintenance, repair/rehabilitation practices, and sustainable decommissioning and disposal at the end of service life.

- Consideration of the overall quality of life, including local productivity, regional, national and international competitiveness, which are all strongly dependent on the quality and performance of the infrastructure

- Ethics considerations, involving elimination of all collusion, corruption and other malpractices in all aspects of infrastructure.

\section{Asset Management}

CIRC 2016 also examined the asset management practices of different municipalities and found that about $90 \%$ of the respondents were using a condition assessment cycle for their infrastructure, while another $62 \%$ assessed their infrastructure at least once every 10 years; however, $10 \%$ had no data on their assets. Fourteen percent of the respondents had formal strategies to incorporate possible future climate change in their infrastructure decisions. Seventythree (73) percent of municipalities had formal asset management programs, including building 
assets, About $90 \%$ of the municipalities used asset management systems for municipal buildings, with $30 \%$ using computer-based systems, while another $16 \%$ used paper-based systems. About $45 \%$ of the municipalities used both systems.

The report found that the municipalities were using different asset management practices according to the community size. Sixty-two percent $(62 \%)$ of large municipalities, $56 \%$ of medium-sized municipalities and $35 \%$ of small municipalities reported using a formal asset management plan. The report noted that all communities, particularly the smaller ones could benefit from increased asset management capacity, with considerable future savings. Some municipalities reported undertaking risk assessments, applying new inspection technologies to assess their infrastructure condition, which would certainly improve the state of Canada's infrastructure.

\section{Canada's Infrastructure Deficit}

The report concluded that despite the tremendous effort by the municipalities, much of Canada's municipal infrastructure is at a critical juncture, needing immediate investments in repair and renovation to prevent escalating decline in its condition. Moreover, the current reinvestment rates are not meeting the target rates, resulting in escalating deterioration and infrastructure deficits, loss of productivity, international competitiveness and overall decline of economy, and quality of life. The replacement costs of infrastructure assets in fair, poor and very poor condition are about C\$388 billion nationally - a very large infrastructure deficit, affecting all economic, social, environmental and budgetary aspects of the life of each Canadian citizen. 


\subsection{Proposed Government Investments}

The present Government of Canada plans to invest C $\$ 123$ billion over the next 10 years to replace the current infrastructure funding programs which have either expired or are about to expire (Infrastructure Canada 2016). The adequacy of these measures needs to be examined. A graphical summary of the infrastructure expenditures (total: $\mathrm{C} \$ 11.9$ billion) in the Federal Government's 2016 Federal Budget is shown in Figure 3.

\subsection{Basic Issues for a National Infrastructure Policy (NIP) for Canada}

Some issues, which need to be addressed by NIP, are reviewed briefly along with some mitigation measures.

\subsubsection{Deferred Maintenance and Non-routine Inspections}

There is an urgent need to ensure that regular maintenance of any infrastructure asset is never deferred under any circumstances. The deferred maintenance has resulted in serious deterioration and occasional failures in many asset types across Canada and around the world. The collapses of de la Concorde Overpass, Laval, Quebec (2006), and the Minnesota Bridge in Minneapolis, Minnesota (2007), both involving loss of life and injuries, due to serious "structural deficiencies", and lack of proper maintenance, resulting from the lack of appropriate timely inspections (Mirza 2006).

\subsubsection{Life Cycle Performance and Cost Analysis}

The observed severe infrastructure deterioration has been blamed partly on the lack of available funds for regular maintenance. Consideration of life cycle performance and costing in planning and design stages must provide funds for maintenance of all asset types over their entire planned service life. A paradigm shift is needed from the current practice of "design, build and forget" to 
"design, build and maintain over the entire service life". These practices should be supported by an appropriate Infrastructure Asset Management System (IAMS) (Uddin et al. 2013).

\subsubsection{Insufficient Investment for Maintenance and Upgrading Infrastructure}

The C\$33 billion Building Canada Plan (BCP 2007-2014) included a C\$17.6 billion allocation to the municipalities for upgrading the existing infrastructure, or development of new infrastructure - approximately C $\$ 2.5$ billion a year (Infrastructure Canada 2016). The needs in these areas are more than $\mathrm{C} \$ 123$ billion and $\mathrm{C} \$ 115$ billion, respectively, over the next 10 to 15 years (FCM, 2007), rendering the federal investment inadequate. All levels of government need to re-evaluate the infrastructure financing and adopt more innovative and sustainable funding sources, such as user fees, debt financing, general taxes, federal and provincial subsidies, crowd funding, adaptive financing and others. BCP has provided C\$1.25 billion for developing a P3 office; efforts should be made to develop more public-private partnerships for all major infrastructure projects. Creation of a Canada Infrastructure Bank to assist with no-interest and low interest loans for infrastructure projects, with strong socio-economic, environmental and regional importance, can help alleviate the current government financial constraints (Infrastructure Canada 2016; Environment Canada 2016; Weber 2016).

\subsubsection{Short-Term Government Funding}

The C\$6 billion Federal Infrastructure Program (1993-1998), shared equally between the three levels of government, helped fund 12,000 projects and created 10,000 jobs (Government of Newfoundland and Labrador 1997). Sixty percent of the program spending was incurred on new infrastructure, although one of the initial objectives was to upgrade the existing municipal infrastructure. However, the consensus among municipalities was that the program helped to 
improve the state of infrastructure in Canada (Siddiqui 1997). The limited success of this program was unfortunately short-lived.

\subsection{Leaders' Views on the Current Infrastructure Crisis}

Hume (2012), a municipal councilor and a commentator, reported on his interviews with selected mayors and Former Prime Minister Paul Martin. A brief summary is presented here to strengthen the case for the proposed infrastructure policy. According to Regina Mayor Pat Fiacco, the upto-date municipal infrastructure deficit in 2012 was about $\mathrm{C} \$ 300$ billion, much higher than the 2007 FCM-McGill estimate of C\$123 billion for existing deteriorated infrastructure, along with another C\$115 billion for new or changed municipal needs; this "was a crushing reality for government and business". He had serious concerns about the ten-year C\$2.1 billion cost of Regina's capital plan, with about $\$ 1.3$ billion remaining unfunded in 2012 . The situation is similar in the rest of Canada. Calgary Mayor Naheed Menshi noted that Calgary’s C\$6 billion capital infrastructure deficit could not be funded by property taxes alone. He emphasized that property taxes were "regressive, feudal and medieval"; they represent the worst form of taxation, which "makes it difficult for the cities to manage themselves". Montreal's former Mayor Gerald Tremblay remarked that Canada was the only G8 country without a transportation plan to address gridlocks in major cities; the annual costs to the local economies in Montreal and Toronto were C $\$ 1.4$ billion and C $\$ 2.5$ billion, respectively.

Hume (2012) observed that "Canada's towns and cities are facing greater challenges than ever, and they seem to have few allies. Generally speaking, the national media have failed to understand or report on the plight of cities and their importance to Canada's prosperity. Excepting for the 1993 and 2015 federal elections, there has been little debate during federal or provincial election campaigns on this major topic. He recommended taking some critical steps to 
improve Canada's infrastructure deficit and the ability of the municipalities to finance the deficit.

These include (Hume 2012):

- A new round of discussions involving all related parties to replace the Canada Building Plan which expired in 2014 (in 2013, it was C\$2 billion annually).

- Change of Canada's taxation system. The municipalities receive only $8 \%$ of the tax dollar, while they are responsible for more than $50 \%$ of Canada's infrastructure.

- Involve the private sector as partner in infrastructure investments through Public-Private Partnerships (PPP's) in infrastructure renewal programs.

- Develop innovative technologies and use the best available technologies to manage and maintain infrastructure.

- Political will to invest in the needed repairs and upgrades.

- Improve management and renewal of infrastructure under federal and provincial jurisdictions.

The former US President Obama addressed the American infrastructure deficit by investing half of the savings resulting from ending of the Iraq war, and the remainder devoted to retiring debt payment (Hume 2012). "In Canada, we seem unable or even unwilling to have this discussion, let alone come to a consensus on the importance or value of such investments. It is hurting our cities, our economy and increasingly will impact our international competitiveness and appeal". Commenting on Canada's ability to compete with the best around the world, Surrey (B.C.) Mayor Dianne Watts questioned, "Will our next generation be the leaders of the world, or laborers of the world?" Canada needs to change its current role of being "the traditional supplier of natural resources and innovate and compete strongly in the global market place". This requires building creative and dynamic cities which would increasingly become international centers. 
Hume (2012) emphasized that "smart investments are needed across Canada now, and a secure, sustainable plan to design and finance them is long overdue".

In commenting on how more financial resources could be made available for infrastructure renewal, the then Finance Minister Paul Martin stated, "Do municipalities want more money from a senior order of government, or do they want the power of new taxation to raise more money and be held responsible".

Based on interviews with a few experts, a recent Financial Post article (2014) finds that the current infrastructure problems have resulted from a combination of the wrong capacity, the wrong technologies and the wrong performance objectives, and proposes a new approach to infrastructure to serve Canada's aging and continuously increasing population (Corcoran 2016). Author, Denise Deveau (2014) suggests that “today's infrastructure is no longer up to the task of handling population growth, urban intensification and climate change. For the most part, it is outdated, overburdened and too "heavy" for the $21^{\text {st }}$ century world". Luigi Ferrara of Toronto's George Brown College stated that "the structural model was developed from ideas that date back to the $19^{\text {th }}$ century, were pioneered in the 1920 's and didn't come into use until the 1950 's". Eva Luigi of the Toronto Clean Air Partnership noted that "while specific infrastructure issues can vary considerably across the country, collaboration is at the heart of generating new ideas" and bringing on innovation to solve infrastructure problems. Stephen Toope, former President and Vice-Chancellor of the University of British Columbia, Vancouver, emphasized the need for a fundamental change by bringing together all interested parties to the infrastructure planning table. He stressed that "it is no longer about a group of engineers designing infrastructure. You have to think about the potential use patterns in a more sophisticated way and how to change those patterns". 


\section{Canada's Priorities and Needed Actions}

The Technology Road Map (2003) provided a list of focused technical and management activities, aimed at improving Canada's infrastructure. However, the various recommended actions, which could be considered part of an infrastructure policy, have yet to receive the urgent attention they deserve. The present infrastructure situation can be improved significantly by encouraging universities and research institutions to undertake research and development aimed directly at developing solutions for Canada's infrastructure problems. A few million dollars a year is too little a price to pay for the overall benefits which will accrue.

Our federal and provincial governments must adopt infrastructure as a very high priority, at par with health, environment and education, otherwise our infrastructure will continue to deteriorate at an alarmingly-escalating rate. As mentioned earlier, the future generations will be left with the burden of rehabilitating whatever deteriorated infrastructure could be salvaged at that time. Some infrastructure facilities could deteriorate to such an extent, that it may not be possible to salvage them, and they would have to be replaced at exorbitantly higher costs by future generations. The interest on the needed additional investment of $\mathrm{C} \$ 2$ or $\mathrm{C} \$ 3$ billion annually on Canada's infrastructure, shared among the different levels of government, would be more beneficial to Canada in every way than the cost of delaying retirement of the accumulated national deficit (Brodhead et al. 2014). Also, Infrastructure Canada, and engineering institutions and learned and professional societies need to provide a much higher level of support to technical activities and dissemination of knowledge related to infrastructure amelioration.

\subsection{Proposed Infrastructure Policy for Canada}

The Government of Canada along with the provincial, territorial and municipal governments, the private sector and all parties with vested interest in infrastructure must acknowledge the looming 
infrastructure crisis, along with its social, economic, political and environmental impacts, and act immediately, before there are more serious consequences. The needed action will help to provide resilience, sustainability and ability to manage the changing infrastructure conditions for the present and future national needs. The principal actions, that need consideration by this group, include:

a) Establishing a commitment by the three levels of government to alleviate the infrastructure crisis at the municipal, provincial/territorial and national levels by eliminating the infrastructure deficit.

b) Assigning a higher priority to infrastructure, at par with health, education, social programs, etc.; provide increased taxation powers for municipalities.

c) Developing increased collaboration and interdisciplinary activities among engineers, urban planners, social scientists, politicians, economists and environmentalists and others to achieve progress in eliminating the crisis, while catering for the present-day issues confronting the nation, such as possible future climate change, escalating oil prices, etc.;

d) Developing a detailed standardized asset inventory for each community (detailed records of construction, maintenance, repair/rehabilitation and distresses) for scientific asset management (TRM 2003).

e) Developing long-range (50-100 years) society infrastructure needs, objectives/goals for infrastructure assets; sustainable funding should be ensured for at least 10 years.

f) Repairing, rehabilitating or replacing existing severely deteriorated assets and establishing, in advance, routine maintenance plans for all future construction; it must be emphasized that maintenance and inspections should never be deferred under any circumstances, whatsoever; funding for maintenance must be assured by the owner at the start of the project. 
g) All new infrastructure facilities should be designed, constructed, operated and maintained over a specified service life, using innovative technologies, highest level of quality control, established best practices and newly developed materials. Depreciation must be included in life cycle costs of all assets and services; this must be accompanied by clear and transparent accounting of all (engineering, economic, environmental and social) costs, besides fulfilling the requirements of sustainable development, involving consideration of all related socioeconomic, cultural and environmental issues, and the impact of any future climate change. Quality control should be of utmost importance in infrastructure conception, design, construction, maintenance, operations, etc.

h) Sustainable development should be encouraged in all phases of a project; the industry should move towards more sustainable and recommended best practices and ensure that these practices continuously adapt to the emerging environmental and possible future climate change issues, and the associated legislations.

i) Encouraging the universities, colleges and other educational and professional institutions to make changes to the civil engineering curricula, to place increased emphasis on all aspects of deterioration, renewal, scientific and sustainable infrastructure management, including design, construction, maintenance, repair/rehabilitation, and decommissioning and sustainable asset disposal at the end of its service life.

j) Life cycle cost analysis (LCCA) should be made mandatory prior to the approval of each project along with standardized inventory tracking and long-term assessments (risk assessments, value engineering, life-cycle cost analysis); it should include asset valuation, depreciation, and risk assessments, and it should be used to implement fair and strategic project prioritization and funding allocations. 
k) The current investment backlog urgently requires innovative sustainable financing sources and creation of a new financing institution, such as a national infrastructure bank, to overcome present shortcomings (Peterson 2009; Mirza 2013); develop a long-term stable financing source to offset instability of current grants and subsidies, and the bond market.

1) All government funding programs should be complementary to a sustained funding source, available through a national infrastructure bank (NIB); NIB should be established by Federal legislation - capital, governance, loans at low or zero interest rates for selected and nationally important projects, e.g., drinking water, sanitation, social housing and other needed infrastructure for the first nations; NIB should make below-market interest loans for infrastructure repairs and other appropriate infrastructure investments, such as low-cost housing badly needed for the homeless across Canada. Long-term user-fee must be based on total or full costs for financing of capital assets; the interest and/or other differentials (from the prevalent market rates) should be absorbed equitably by the different levels of government.

m) Capital financing should be linked to long range capital planning based on infrastructure assessments, maintenance requirements, and immediate investment priorities. Provinces and local governments should have flexibility to develop local priorities for "catch-up" investment

n) The appropriate financing alternative should be selected based on the criteria of efficiency, equity, effectiveness, environmental sensitivity, innovation, accountability and administrative costs.

o) Each citizen is entitled to safe drinking water, safe disposal of sewage, solid and hazardous waste, and safe and serviceable roads, bridges and other infrastructure. Establish new or 
upgrade the existing national water, sanitation, and transportation policies with legally regulated minimum standards, consistent with the United Nations stipulations.

p) The user must pay appropriately for all benefits received on the basis of equity, economic efficiency, accountability and transparency.

q) Establish centers of excellence to undertake research and development to deal with local, regional and national needs, and other relevant topics, and to provide advice to infrastructure managers, technical personnel, decision-makers and others on all infrastructure issues.

\subsection{National Benefits}

It must be reemphasized that nation-building, international competitiveness and a superior quality of life cannot be maintained without safe and serviceable infrastructure to support everyday activities and the services essential for sustainable development and human survival. Addressing these issues with an NIP would provide specific benefits, namely:

a) Assurance that changes are made across the country, thereby equitably promoting development nation-wide;

b) The public and private sectors should adopt procedures dealing with:

- Improved asset management (AM) practices, including LCCA, inventory tracking, risk assessment, etc.

- Funding allocations to be ameliorated with the information provided by a complete inventory of all assets and the information from AM practices.

- Eliminating deferred maintenance, accompanied with performing LCCA and considering innovative funding alternatives, which in turn, promote sustainability; 
- Developing AM practices that support long-term planning would be incomplete without the possible future climate change considerations, which promote resilience and a longer asset service life. Innovative funding mechanisms would not only help provide funds for upgrading existing deteriorating infrastructure and new infrastructure needs, but it would also ensure that funds are available to perform scientific AM practices.

\subsection{Needed Resources}

Strategic investments are needed presently to ensure that more funds are being directed to the upgrading of severely deteriorating assets, and to help improve the technical expertise and practices that support sustainable infrastructure management. Funds will also be needed for implementation, training and education of the needed new personnel and the municipalities - an initiative that has many long-term economic benefits, such as:

- Creation of tens of thousands of jobs due to the establishment of the new council and related offices, and the infrastructure bank, and in the related areas of public works.

- Alleviation of non-strategic allocation of funds with improved project prioritization and a detailed inventory of all assets.

- Prevention of deterioration from reaching unacceptable levels through routine maintenance, preventing an early replacement of the assets at much higher costs than the costs needed to perform regular maintenance on an annual basis.

- Savings of time and resources and a significant improvement in asset management practices by maintaining a detailed GIS- based inventory of all infrastructure.

- Elimination or at worst minimization of infrastructure-related tragedies and the associated costs to the society. 
It is essential to re-evaluate the available infrastructure financing; more innovative and sustainable sources of financing are needed. A significant highlight of the $\$ 33$ billion Building Canada Plan was to establish a P3 office to encourage the use of public-private partnerships (PPP or P3s) as an alternative. Strategic investment in infrastructure in upcoming government budgets and allocation of funds from the yearly surpluses should be considered by all levels of government. In addition, an infrastructure bank should be established, similar to those already established in some states in the United States. As mentioned earlier, low or no interest loans can be provided to urgent infrastructure projects based on their socio-economic and environmental significance. The infrastructure bank should recycle the loan repayments for future projects to provide a sustained funding source. Short-term infrastructure financing programs should be only complementary to the regular programs financed by the infrastructure bank. Therefore, if a government program expires, funds would always be available to meet the upgrading and new needs. Operation of the bank should include project application and selection process to fund selected projects from the capitalization reserve through low-interest loans and credit enhancements.

\subsection{Education and Awareness}

The proposed NIP and Infrastructure Bank proposals can be implemented successfully only with support from all sectors, including the public and private sectors and the academia.

\subsubsection{Public Awareness and Commitment}

Grey County, Ontario, with a population of 60,000 residents, initiated the Closed Loop Tire Recycling Project in 1993, a program that utilizes used tires as recycled material in asphalt pavements. Grey County discovered many advantages of rehabilitating severely deteriorated 
roads by adding recycled tires to the asphalt mixture, while counteracting the environmental and health threats from the county's scrap tire problem. The project would certainly help any residents wishing to discard their tires, but the local residents needed to be persuaded to commit to such an initiative.

Informing politicians, landfill dealership owners and residents was an essential part of this program. The community was made aware of the details of the project, as well as its benefits through advertisements and public presentations. Reluctant tire dealers were soon persuaded to become committed contributing companies and were highlighted on posters showing their environmental commitment. This project has proved the commitment of the community in making it more sustainable.

\subsubsection{Academia}

Presently, only a few universities offer specific courses dealing with infrastructure deterioration and condition assessment techniques, along with socio-economic, environmental, financial, management and other issues related to infrastructure. Introduction of an NIP would require standardized condition assessments, inventory development and other practices, which would require the universities to include the relevant courses dealing with urgent needs in their civil engineering curricula. It is recommended that the civil engineering curriculum be expanded to include:

- Standardized condition assessment techniques for various infrastructure categories, with reference to the different types of material deterioration under various aggressive environments.

- The NIP with its recommendations. 
- Asset management systems for the various infrastructure types.

- Relevant environmental, socio-economic and political aspects of infrastructure and all related sustainable development issues.

- Consideration of life-cycle performance and costing, depreciation and valuation techniques, and risk assessment for all infrastructure assets; optimization strategies for the best decisionmaking options over the service life of the asset, and all related environmental and sustainability issues.

In addition, a special graduate level program, should be introduced, integrating the needs from different types of infrastructure assets aimed at training students to deal with all aspects of infrastructure issues, along with an internship program.

\subsection{Best Practices}

It is essential that the required tools are made available to practitioners to effectively manage infrastructure assets in their community. Canada has been a leader in developing several best practices for amelioration of Canada's infrastructure. The best practices, developed by over 300 expert volunteers for InfraGuide (2001-2007), have been extremely well received internationally; more resources and supporting regulations are needed to guide these and other experts to develop the protocols necessary for improved infrastructure management practices. The InfraGuide could be considered a stepping stone from which researchers can develop updated and new best practices and modeling of information systems to support these practices. The best practice guidelines and the associated protocols would have to be continually updated to fulfill any new needs resulting from the changing needs of the community, population growth, possible climate change, new environmental regulations, suburban sprawl, etc. 


\section{Summary and Conclusions}

Building for the present and future communities requires long-term planning, including projected changing community needs, population growth, keeping up with the technological innovations, and dealing with increasing impact of extreme weather events, and ensuring delivery of essential public services without disruption. After examination of the deteriorated state of Canada's deteriorating infrastructure, along with that in the U.S.A. and the world, the infrastructure deficits and consequences of inaction, and the views of community and political leaders to establish infrastructure priorities and needed actions, an NIP is proposed for consideration by all parties dealing with infrastructure. Creation of an infrastructure bank is recommended to overcome the prevailing infrastructure crisis.

A review of the extensively deteriorated state of Canada's aging infrastructure, caused by prolonged neglect and deferred maintenance, repair and rehabilitation, along with the lack of any serious concern by the different levels of government, is presented. This has decreased infrastructure service life considerably, and in some cases, it has led to tragic failures and serious distresses with loss of life, injuries and serious economic setbacks. The associated financial needs to upgrade the infrastructure to an acceptable level are examined, along with the consequences of any delay in the needed repairs and renewal.

Implementing an NIP would be a very complex task, especially with the recommendation of establishing an infrastructure bank. Public awareness campaigns at all stages of policy implementation would be needed to convince the population that their tax-dollars and the Government commitments are progressing in the right direction. 


\section{Acknowledgements}

The authors would like to recognize and thank their research group members, including Sagheer Aslam, Adriana Giannini, Mahnaz Sadri, Sadaf Siddiqui, Cristian Sipos, and others who undertook research on the various infrastructure issues during their graduate studies under the supervision of Professor Mirza. The stimulating discussions with several colleagues on the InfraGuide, the Federation of Canadian Municipalities and the Canadian Society for Civil Engineering, and other engineers, economists and other professionals, and the published views of the various community and political leaders, whose ideas may have been incorporated directly or indirectly in this paper, are gratefully acknowledged.

\section{References}

American Society for Civil Engineers - ASCE 2013. Report Card for America's Infrastructure. Available from www.infrastructurereportcard.org/[Accessed 20 June 2016].

Brodhead, J., Darling, J. and Mullin, S. 2014. Crisis and Opportunity: Time for a National Infrastructure Plan for Canada. Available from http://canada2020.ca/crisisopportunitytimenationalinfrastructureplancanada/ [Accessed 20 June 2016].

Dunlop, T. 2008. Infrastructure Australia. Available from http://blogs.news.com.au/news.

The Economist. Available from www.economist.com/news/economic-and-financialindicators/21647313-natural-disasters [Accessed 20 June 2016].

Deveau D. 2014. United they stand: Canadian cities collaborating to take on deluge of water challenges, Financial Post. Available from http://business.financialpost.com [Accessed 9 May 2016]. 
Environment Canada 2016. Available from www.ec.gc.ca/meteo-weather/[Accessed August 2016].

Federation of Canadian Municipalities - FCM 2006. Building Prosperity from the Ground Restoring Municipal Balance. Available from www.fcm.ca/Documents/reports/[Accessed 20 June 2016].

Federation of Canadian Municipalities - FCM 2008. Infrastructure as Economic Stimulus. Available from www.fcm.ca/Documents/reports/[Accessed 20 June 2016].

Federation of Canadian Municipalities - FCM 2009. Infrastructure Projects Key to Putting Canadians to Work. Available from www.fcm.ca/Documents/reports/[Accessed 20 June $2016]$.

Federation of Canadian Municipalities - FCM 2012. State of Canada's Cities and Communities. Available from www.fcm.ca/Documents/reports/[Accessed 20 June 2016].

Finance Canada 2011. Canada's Economic Action Plan: A Seventh Report to Canadians. Available from www.fin.gc.ca/pub/report-rapport [Accessed 20 June 2016].

Federation of Canadian Municipalities - FCM 2016. Informing the Future: The 2016 Canadian Infrastructure Report Card (CIRC-2016). Available from http://canadainfrastructure.ca/ [Accessed 5 September 2016].

Corcoran, T. 2016. The real gaps in Canada's infrastructure, Financial Post. Available from http://business.financialpost.com/fp-comment/terence-corcoran-the-real-gaps-in-canadas$\underline{\text { infrastructure }}$ [Accessed 20 January 2016]

Gagnon, M., Gaudreault, V., and Overton, D. 2008. Age of public infrastructure: A provincial perspective. Statistics Canada: Investment and Capital Stock Division. 
Government of Newfoundland and Labrador 1997. Our budget plan. Available from http://www.budget.gov.nl.ca/budget97/ourplan.htm [Accessed 8 June 2016].

Hill, J. S., Chae, M. S., and Park, J. 2012. The effects of geography and infrastructure on economic development and international business involvement. Journal of Infrastructure Development, 4(2), 91-113.

Hume, G., 2012. Prosperity or bust: The need to renew Canada's infrastructure, Ivey Business Journal, Issues: May / June 2012. Available from http://iveybusinessjournal.com/publication/prosperity-or-bust-the-need-to-renew-canadasinfrastructure/ [Accessed 15 May 2016].

InfraGuide, 2007. The National Guide to Sustainable Infrastructure. Federation of Canadian Municipalities, Ottawa, Canada.

Infrastructure Canada, 2016. 2014 New building Canada plan. Available from www.infrastructure.gc.ca. [Accessed 20 June 2016].

Infrastructure Council of Manitoba 2000. National Highway Policy. Winnipeg Manitoba, Canada.

Mirza, S., 1998. Canada's Deteriorating Infrastructure: A Case for National Infrastructure Policy. Manitoba Heavy News Annual, Manitoba Heavy Construction Association, Winnipeg, Manitoba, Canada.

Mirza, S., 2006. Durability and Sustainability of Infrastructure - a State-of-the-Art Report. Canadian Journal of Civil Engineering, 33(6). Ottawa, Canada.

Mirza, S. 2007. Danger Ahead: The Coming Collapse of Canada's Municipal Infrastructure. Federation of Canadian Municipalities (FCM), Ottawa, Canada. 
Mirza, S. 2013. A national infrastructure bank for Canada, Canadian Civil Engineer, Spring Issue $30.1,19-20$.

McKinsey Global Institute - MGI 2013a. Smarter Infrastructure Spending Needed for Growth. MGI, London, U.K. Available from www.mckinsey.com [Accessed 20 June 2016].

McKinsey Global Institute - MGI 2013b. Infrastructure Productivity. Available from www.mckinsey.com [Accessed 20 June 2016].

Newman, L., Ling, C., \& Dale, A. 2008. Does Place Matter? Sustainable Community Development in Three Canadian Communities.

Oliver, A. 2015. UK infrastructure asset value slips behind the G7 national average, Infrastructure Intelligence. Available from http://www.infrastructureintelligence.com/article/oct-2015/uk-infrastructure-asset-value-slips-behind-g7-nationalaverage [Accessed 10 July 2016].

Peterson, G. E., 2009. Unlocking land values to finance urban infrastructure. Vol. 7, World Bank Publications.

Siddiqui, S., 1997. Infrastructure, Sustainable Development \& Society. M. Eng. Thesis. Department of Civil Engineering and Applied Mechanics, McGill, Montreal, Canada.

Swiss Re Economic Research \& Consulting and Cat Perils - SWISSRE 2016. Available from www.swissre.com/sigma/ [Accessed 20 May 2016].

The Technology Road Map - TRM 2003. Civil Infrastructure Systems: Technology Road Map (2003-2013).

Uddin, W., Hudson, W., and Haas, R. 2013. Public infrastructure asset management. McGraw Hill Professional. 
UK National Infrastructure Plan 2013. HM Treasury, United Kingdom. Available from www.gov.uk/government/[Accessed 20 June 2016].

Weber, B. 2016. Infrastructure as an Asset Class: Investment Strategy, Sustainability, Project Finance and PPP. John Wiley \& Sons.

\section{List of Figures}

Figure 1: Estimates of needed infrastructure investment, 2013-30 (Source: Organization for Economic Co-operation and Development (OECD); International Energy Agency (IEA), 2011; International Transport Forum (ITF); Global Water Intelligence (GWI); McKinsey Global Institute).

Figure 2: Insured catastrophe losses, 1996 - 2015, in USD billion at 2015 prices (The Economist 2016; SWISSRE 2015).

Figure 3: Breakdown of Government of Canada 2016 federal infrastructure budget (Phase-1 of Infrastructure Plan of 10-year infrastructure funding) (Infrastructure Canada 2016). 
Table 1: Past Infrastructure Deficit Estimates for Canada (CIRC 2016; FCM 2012; FCM 2009;

FCM 2008; Mirza 2007; FCM 2006; TRM 2003).

\begin{tabular}{ccl}
\hline Year & $\begin{array}{c}\text { Deficit } \\
\text { (C\$Billion) }\end{array}$ & \multicolumn{1}{c}{ Comments } \\
\hline 1985 & 12 & FCM survey results. \\
\hline 1992 & 20 & FCM survey results. \\
\hline 1995 & 44 & Detailed FCM- McGill survey results. \\
\hline 2003 & 57 & $\begin{array}{l}\text { Technology Road Map (TRM), Canadian Society for Civil Engineering } \\
\text { (CSCE), Canadian Council of Professional Engineers (CCPE), Canadian } \\
\text { Public Works Association (CPWA) and the National Research Council of } \\
\text { Canada (NRC) - Upgrading of 1995 FCM- McGill survey results. }\end{array}$ \\
\hline 2007 & 123 & $\begin{array}{l}\text { FCM-McGill Survey } \\
\text { Upgrading of deteriorated municipal infrastructure. }\end{array}$ \\
& 115 & $\begin{array}{l}\text { Estimated needs for new municipal infrastructure Provincial/Territorial } \\
\text { and Federal Infrastructure renewal and needs for new infrastructure } \\
\text { (42/58 } \times 100 \%) 72.4 \% \text { of municipal infrastructure needs. }\end{array}$ \\
\hline 2012 & 172 & $\begin{array}{l}\text { CIRC (CCA, CPWA, CSCE \& FCM) - Results of survey of drinking- } \\
\text { water, wastewater and storm water infrastructure, and municipal roads } \\
\text { (2009-10) showed that 30\% of these assets were between fair and poor } \\
\text { condition with a replacement cost of C\$ 172 nationally. }\end{array}$ \\
\hline 2016 & 388 & $\begin{array}{l}\text { CIRC (CCA, CPWA, CSCE, FCM \& CUTA) - Results of survey of } \\
\text { municipal roads and bridges, public transit, buildings, sport and } \\
\text { recreation facilities, storm water, wastewater and drinking water } \\
\text { infrastructure showed that 30\% of these assets were between fair and very } \\
\text { poor condition with a replacement cost of C\$ \$416 nationally for } \\
\text { upgrading one-third of these assets to an acceptable level of performance } \\
\text { (good). }\end{array}$ \\
\hline
\end{tabular}


Table 2: Infrastructure Needs - World, U.S.A. and Canada (in Trillion Dollars, excepting where specified in billions for Canada's infrastructure)

\begin{tabular}{|c|c|c|c|}
\hline & On Date & $\begin{array}{l}\text { In } 2016 \\
\text { US \$ }\end{array}$ & $\begin{array}{l}\text { In } 2016 \\
\text { CAN } \$\end{array}$ \\
\hline World (2010 US \$) & $\$ 57-67$ & $\$ 70-82$ & $\$ 90-105$ \\
\hline USA (2013 ASCE Report) & $\$ 3.6$ & $\$ 4$ & $\$ 5$ \\
\hline \multicolumn{4}{|l|}{2007 (FCM-McGill) } \\
\hline $\begin{array}{l}\text { Rehabilitation of deteriorated } \\
\text { infrastructure }\end{array}$ & \$123b (US \$96b) & $\$ 126 \mathrm{~b}$ & $\$ 162 \mathrm{~b}$ \\
\hline $\begin{array}{l}\text { Projected } \mathrm{F} / \mathrm{P} / \mathrm{T} \text { needs at } 0.724 \text { of } \\
\text { municipal needs }\end{array}$ & $\$ 93 b(\mathrm{US} \$ 73 b)$ & $\$ 90 \mathrm{~b}$ & $\$ 115 b$ \\
\hline New needs & $\$ 115 b(\mathrm{US} \$ 96 b)$ & $\$ 118 b$ & $\$ 150 \mathrm{~b}$ \\
\hline Projected F/P/T needs & $\$ 85 b(U S \$ 67 b)$ & $\$ 93 \mathrm{~b}$ & $\$ 120 \mathrm{~b}$ \\
\hline Total needs (2007) & & $\$ 427 \mathrm{~b}$ & $\$ 547 \mathrm{~b}$ \\
\hline \multicolumn{4}{|c|}{2012 CIRC $(30 \%$ of municipal infrastructure in fair, poor to very poor condition } \\
\hline Rehabilitation needs & $\$ 172 b(U S \$ 134 b)$ & $\$ 150 \mathrm{~b}$ & $\$ 190 \mathrm{~b}$ \\
\hline Projected F/P/T needs & $\$ 127 b(\mathrm{US} \$ 99 b)$ & $\$ 115 b$ & $\$ 144 \mathrm{~b}$ \\
\hline Total needs (2012) & $\$ 271 \mathrm{~b}$ & $\$ 265 \mathrm{~b}$ & $\$ 334 \mathrm{~b}$ \\
\hline \multicolumn{4}{|c|}{2016 CIRC (33\% of municipal infrastructure in fair, poor to very poor condition) } \\
\hline Rehabilitation needs & $\$ 388 \mathrm{~b}(\mathrm{US} \$ 303)$ & $\$ 303 \mathrm{~b}$ & $\$ 388 \mathrm{~b}$ \\
\hline Projected F/P/T needs & $\$ 230 b(\mathrm{US} \$ 180 \mathrm{~b})$ & $\$ 224 b$ & $\$ 287 \mathrm{~b}$ \\
\hline Total needs (2016) & $\$ 618 b(\mathrm{US} \$ 483 \mathrm{~b})$ & $\$ 569 \mathrm{~b}$ & $\$ 675 \mathrm{~b}$ \\
\hline
\end{tabular}


\$ trillion, constant 2010 dollars

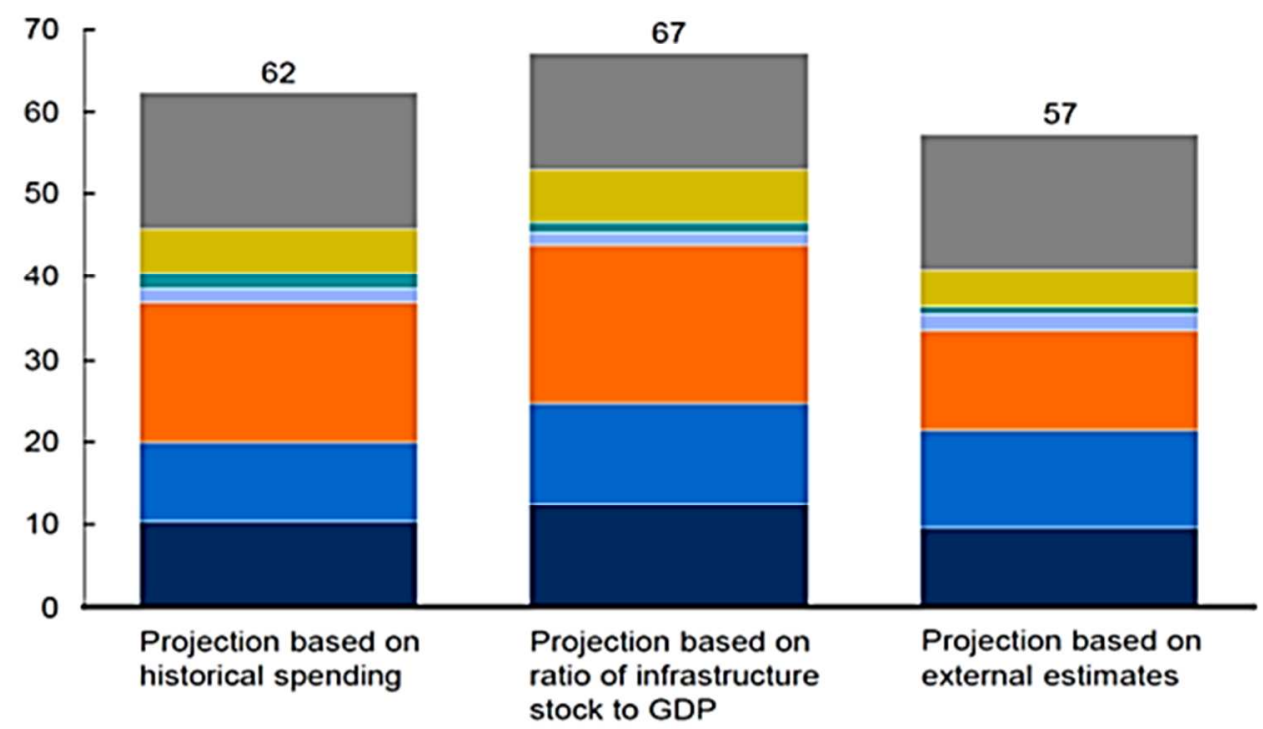

$\square$ Roads

$\square$ Rail

$\square$ Ports

$\square$ Airports

$\square$ Power

$\square$ Water

Delecom ratio of infrastructure external estimates stock to GDP 


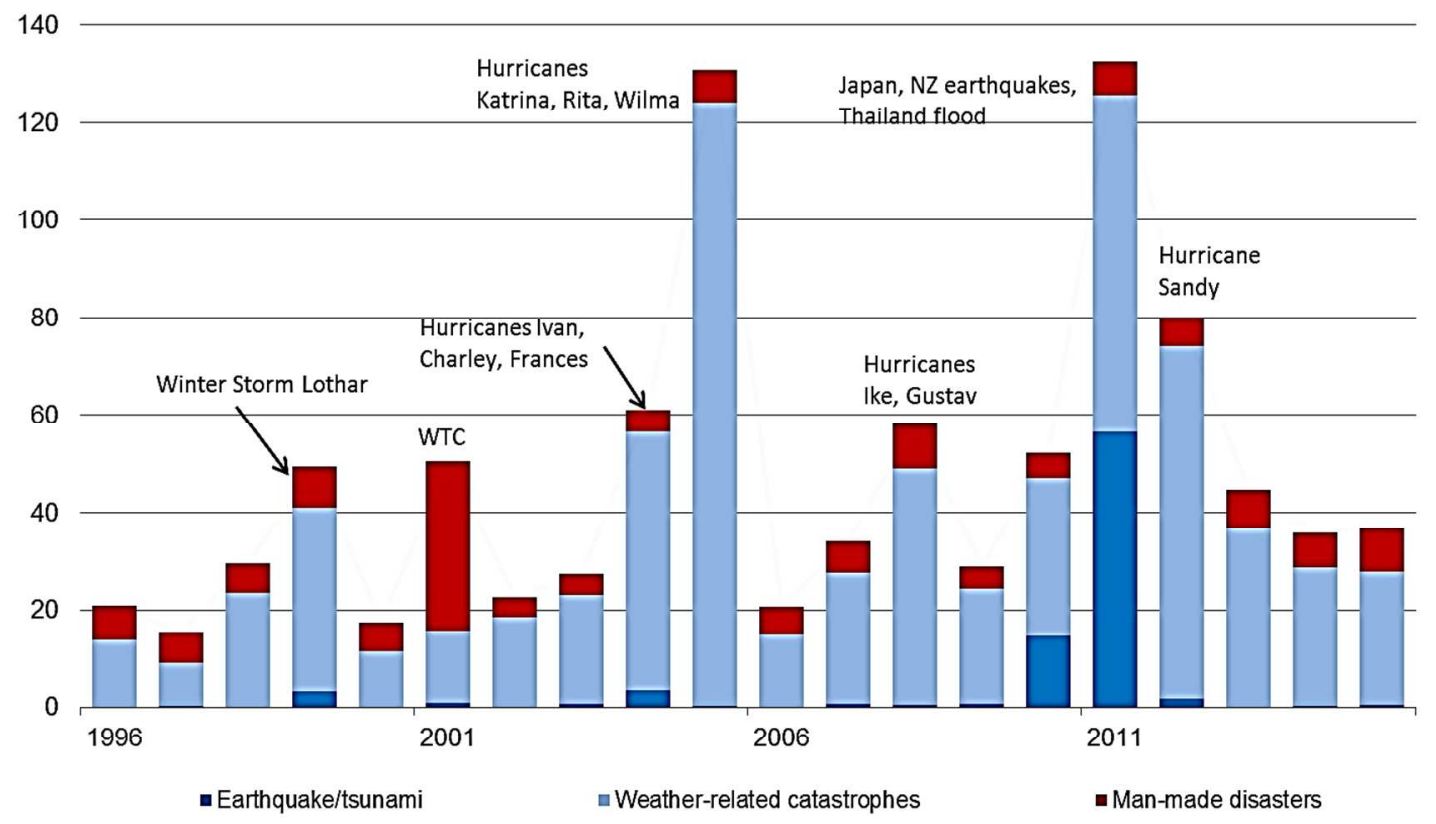




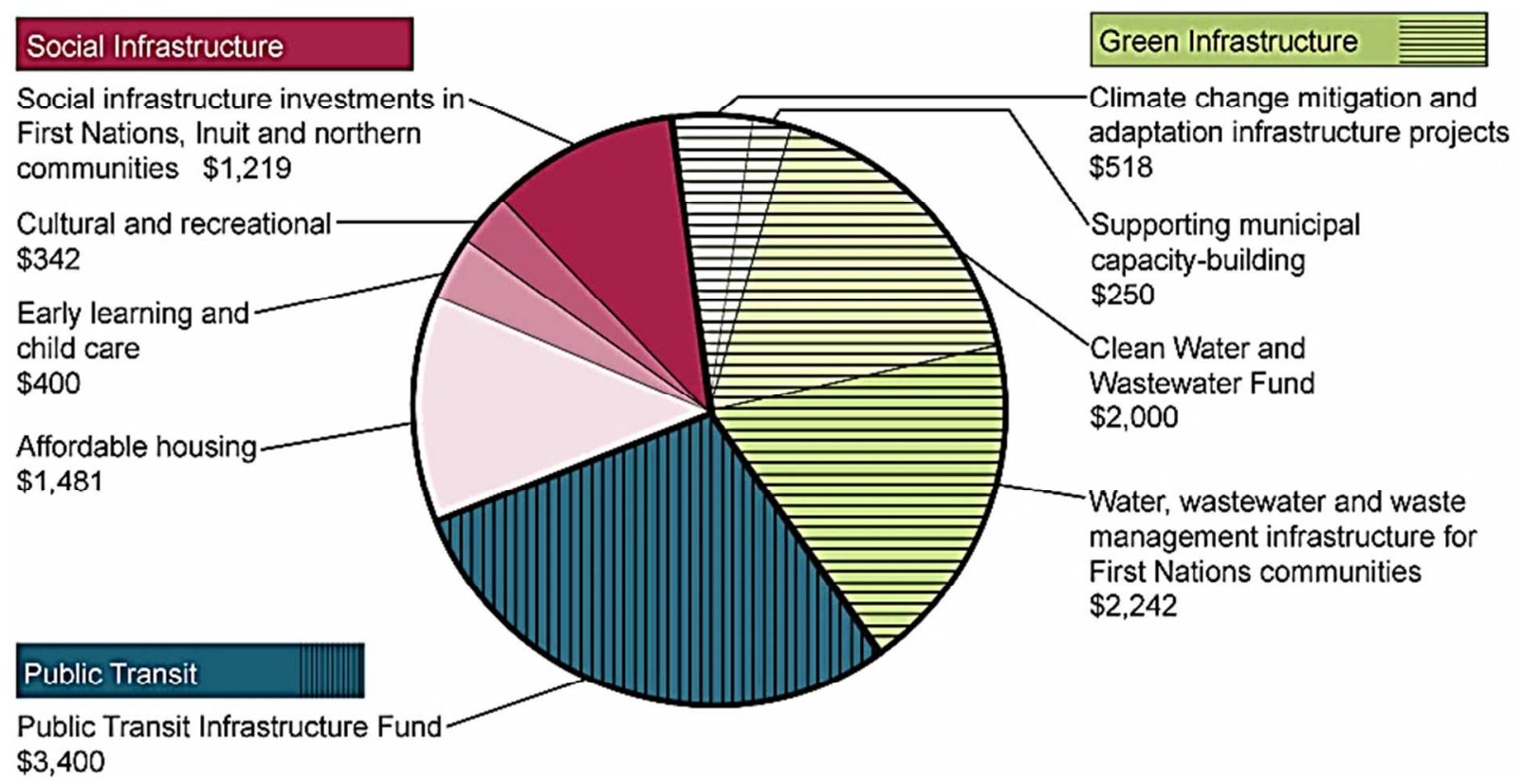

